\title{
Seismic Precursors to the Whakaari 2019 Phreatic Eruption detected in Five Other Volcanoes
}

\author{
Alberto Ardid ( $\square$ aardids@gmail.com ) \\ University of Canterbury \\ David Dempsey \\ University of Canterbury https://orcid.org/0000-0003-2135-5129 \\ Corentin Caudron \\ Université Libre de Bruxelles \\ Shane Cronin \\ University Auckland https://orcid.org/0000-0001-7499-603X
}

\section{Article}

Keywords: Volcano seismology, eruption precursors, time-series feature engineering, sealing

Posted Date: November 30th, 2021

DOI: https://doi.org/10.21203/rs.3.rs-1101606/v1

License: (9) This work is licensed under a Creative Commons Attribution 4.0 International License. Read Full License 


\section{Abstract}

Volcanic eruptions that occur without warning can be deadly in touristic and populated areas. Even with real-time geophysical monitoring, forecasting sudden eruptions is difficult because their precursors are hard to recognize and can vary between volcanoes. Here, we describe a general seismic precursor signal for gas-driven eruptions, identified through correlation analysis of 18 well-recorded eruptions in New Zealand, Alaska and Kamchatka. We show that the displacement seismic amplitude ratio, a ratio between high and medium frequency volcanic tremor, has a characteristic rise in the days prior to eruptions that likely indicates formation of a hydrothermal seal that enables rapid pressurization. Applying this model to the fatal 2019 eruption at Whakaari (New Zealand), we identify pressurization in the week before the eruption, and cascading seal failure in the 16 hours prior to the explosion. This method for identifying and proving generalizable eruption precursors can help improve short term forecasting systems.

\section{Introduction}

Sudden, gas-driven explosions occur with little warning in volcanic areas and have caused recent loss of life in Japan (2014 Mt Ontake eruption, 58 deaths; Yamaoka et al., 2016) and New Zealand (2019 Whakaari eruption, 22 deaths; Dempsey et al. 2020). Whakaari is an andesitic stratovolcano island located at the northern end of New Zealand's Taupo Volcanic Zone (TVZ) (Figure 1). It is one of the country's most active volcanoes with a long history of fumarolic activity, interspersed with sudden phreatic, phreatomagmatic and magmatic eruptions (Houghton et al., 1991; Kilgour et al., 2021). Despite this history and real-time monitoring, identification of eruption precursors and early warning at this and similar volcanoes remains challenging.

Phreatic eruptions are driven by expansion and steam-flashing of suddenly released hot pressurized groundwater fluids (e.g., Montanaro et al., 2016). Containment arises through sealing of a liquid water, magmatic gas or steam reservoir under diverse settings such as: low-permeability layers forming below crater lakes or within crater basins (clay/silt deposits, liquid sulphur; Christenson et al., 2010); hydrothermal alteration changing rock texture/permeability (Heap et al., 2017;); pore-blockage by elemental sulphur or hydrothermal precipitates (Christenson and Wood et al., 1993; Kilgour et al., 2010; Scolamacchia and Cronin, 2016); and/or active sealing by pressure applied to compressible clays (Kanakiya et al., 2021). Permeability barriers become even more important if gas input increases during magmatic unrest. Restriction of gas flow through the upper vent system leads to localized shallow pressurization, creating the conditions for an explosive eruption.

Seismic data analysis is standard practice at volcano observatories to track magmatic processes, volcano state and the possibility of future eruptions (Chouet, 1996; Konstantinou and Schlindwein, 2003; Jellinek and Bercovici, 2011; Fee et al., 2017; Caudron et al., 2021). Continuous volcanic tremor signals are targeted to understand fluid movement, such as during magma degassing, conduit fracture/bubble processes that precede eruptions, and pressurization of a hydrothermal system (Gottsmann et al., 2007; Ohminato et al., 2006; Caudron et al., 2019). However, for continuously active, seismically noisy and "wet" 
volcanoes (Gunawan et al., 2017), tremor prior to phreatic or phreatomagmatic eruptions are difficult to distinguish, or only identified in retrospect (Christenson and Wood, 1993; Christenson et al., 2010; Pardo et al., 2014; Dempsey et al., 2020; Yamada et al. 2021). This is partly due to the very shallow origin of these "small" explosions, with pressurization and triggering within a few tens to hundreds of metres of the surface (Montanaro et al., 2016; Jolly et al., 2020; Caudron et al., 2021). Signals are also dampened by formation of low-permeability seals (Christenson and Wood et al., 1993; de Moor et al., 2019). Quietening of a system can impart a false sense of safety if fluids are being trapped/pressurised. A sudden pulse of additional magmatic gas may rupture these systems, but eruption initiation can also be any process that causes decompression, such as surface-propagating drying/cooling cracks, tectonic fracturing, sudden overburden loss due to landslides (Montanaro et al., 2016) or lake breakouts.

Tremor data, usually between $0.1-25 \mathrm{~Hz}$ (Endo and Murray, 1991; Konstantinou and Schlindwein, 2003), is typically analysed within frequency bands. Real-time seismic amplitude measurement (RSAM) and reduced displacement uses the 2-5 Hz range (Aki and Koyanagi, 1981; McNutt, 1994) for short-term forecasting (Chardot et al., 2015; Reichstein et al., 2019; Hajian et al., 2019; Dempsey et al., 2020). Medium (MF; 4-8 Hz) and high-frequency bands (HF; 8-16 Hz), and their ratios are used to interpret seismic attenuation in relation to source effects and source changes (Caudron et al., 2019). The displacement seismic amplitude ratio (DSAR; MF/HF) has been linked to month- and year-long variability prior to eruptions (Caudron et al., 2019; Caudron et al., 2021), interpreted as progressive sealing and tendency to pressurization. To evaluate these continuous signals, pattern-recognition, clustering, neural network and failure-forecasting tools are used (Langer et al., 2016; Brancato et al., 2019; Dempsey et al., 2020). In particular, time-series feature engineering may reveal hidden, but statistically relevant patterns in complex time series (Dempsey et al., 2020).

Here, we analysed tremor time-series prior to 18 eruptions at six volcanoes: Whakaari, Ruapehu and Tongariro (New Zealand), Veniaminof and Pavlof (Alaska, USA), and Bezymiany (Russia) (Figure 1). We used feature engineering to extract latent patterns from the tremor and then systematically mined these for significant correlations across all volcanoes in the weeks prior to eruptions (see Methods). We identified characteristic peaks in a 2-day smoothed and normalized DSAR tremor (nDSAR; see Methods) that recurred with greater strength and frequency prior to eruptions at several volcanoes. By considering other data and analyses of the 2019 Whakaari eruption, we propose that this pattern indicates rapid sealing in the shallow hydrothermal system, which ultimately led to pressurization and a fatal phreatic explosion.

\section{Results}

\section{Correlations of pre-eruptive time-series features}

In the four weeks leading up to an eruption, we observe potentially correlated patterns across at least three classes of derived tremor time series (see Methods). Prior to six major eruptions (VEI >2) at each of the studied volcanoes, there is a sustained elevation of nDSAR rate variance between 5 and 10 days prior 
to the event (Figure 1; see Figure $\mathrm{S} 1$ for equivalent time series on all eruptions). This behavior is not obvious in the raw data, but it indicates a change in the system state so that it is conducive to more voluminous sealing or pressurization with comparatively larger gas explosions.

A second archetypal pattern occurs in the nDSAR median, one week before eruptions (Figure 2). Patterns of Whakaari-2019 and Veniaminof-2013 are especially similar. Both records exemplify a steady rise of $n D S A R$ median to peak a few days prior to the eruption. The eruption itself often occurs after a day or two of decline. We quantify similarity in the pattern shape between pairs of eruptions by calculating the crosscorrelation coefficient, $C C$, for the 4-week records prior to eruption. For the Whakaari-2019 and Veniaminof-2013 eruption pair, $C C=0.71$. The smoothed $n D S A R$ pattern is broadly similar across all studied volcanoes with some variability in the timing, width and magnitude of the peak, which produces a range of $C C$ values (Figure 2a). The greatest similarity is seen between Whakaari, Veniaminof, and Ruapehu volcanoes, whereas Tongariro, Pavlof and Bezymiany, show a self-similar pattern of several decreasing cycles of the nDSAR median in the month before their eruptions.

The third pattern is observed as an increased strength of 75-min oscillations in $n H F$ tremor, with similar timings prior to several eruptions as Whakaari 2016, 2019, Ruapehu 2009, and Bezymiany 2007a-b (See Figure S4). These eruptions were dominated by strong activity around two days prior with inverse RSAM exhibiting a linear decline (Figure S5), indicative of cascading material failure (Voight, 1988; Chardot et al., 2015). In the next section, we show that correlation in this particular time series is spurious.

\section{Statistical significance of possible eruption precursors}

Demonstrating that a common pattern occurs prior to multiple events (i.e., is recurrent) is the first step in establishing an eruption precursor. To be transferable, it should also occur prior to eruptions at multiple volcanoes. The $n D S A R$ rate variance and $n D S A R$ median are both recurrent and transferable (Figures 1 and 2). A third property of an eruption forecaster is that the pattern should also be rare (or absent) during non-eruptive unrest, or volcanic repose.

We tested whether $C C$ values prior to eruptions were unusual during repose periods at the volcanoes (see Methods). If there is a statistically significant deviation, this indicates a higher degree of pattern recurrence prior to eruptive periods than expected by chance. We tested the nDSAR median pattern in the four weeks* prior to the Whakaari 2019 eruption (Figure 2b) for differentiability by convolving it with the entire Whakaari, Ruapehu, Tongariro and Veniaminof records** to generate distributions of $C C$ (Figure 3a; *see Figure S5 for equivalent analysis over three and five weeks; **volcanoes were selected for the statistical analysis given their extended records, see Table S1). We found this pattern had high correlation prior to the four other eruptions at Whakaari, with values exceeding the distribution 90th percentile. Further, with a p-value $<0.001$ (Table S3), these values are highly likely to belong to a different distribution than that of the inter-eruptive record. Eruptions at Ruapehu, Tongariro, and Veniaminof also rank highly in a percentile-sense, but the strength of dissimilarity is lower ( $p$-values of $0.017,0.066$ and 0.072 , respectively), possibly because there are fewer recorded eruptions. 
A similar test was applied to the nDSAR rate variance pattern (Figure 1), again taking four weeks prior to the Whakaari 2019 eruption as the common measure of correlation (Figure 3b). Results suggest recurrency and differentiability of this pattern among the Whakaari eruptions, with all ranking above the 80th percentile ( $p$-value of 0.006 ), but a much reduced degree of transferability to Ruapehu, Tongariro and Veniaminof eruptions ( $p$-values between 0.094 and 0.149 ).

Finally, the 75-minute nHF harmonic prior to the Whakaari 2019 eruption (Figure S4) was found to not be statistically significant (Figure 3c). Although strong activity is observed several days before six different eruptions (see Figure S4), this is not readily differentiable from other episodes that occur during repose.

\section{Inferring eruptive processes in the Whakaari 2019 eruption}

Statistical analysis indicates an archetypal pattern of $n D S A R$ median across multiple volcanoes (Figure $2 b$ ), increasing to a peak 2-4 days before an eruption. We use observations of the 2019 Whakaari eruption to explain this pattern in the context of the active hydrothermal system and aquifer within crater fill deposits above the vent. Specifically, we identify transitions between five regimes or state: (1) interaction and gas exchange between magmatic and geothermal systems, (2) pulsating gas release at the surface, (3) seal consolidation, (4) aquifer pressurization, and (5) seal breakdown and eruption (Figure 4; See Table S4).

A sustained RSAM harmonic signal lasting minutes to days (identified as "volcanic tremor"; Chouet, 1996), was detected at Whakaari between Nov 10 and 23 (regime 1, Figure 4c). This signal is considered to indicate interactions between the magma source (estimated to be 0.8-1.0 km deep at Whakaari; Jolly et al., 2018) and the groundwater (geothermal aquifer). At the surface (GeoNet, 2019a) geysering began and the crater lake level rose. On Nov 18, the Volcano Alert Level (VAL) was raised from 1 to 2, its highest noneruptive category (Potter et al., 2014).

Transition to a new regime is marked by an RSAM decrease, and concurrent increases in MF and HF after Nov 23. This was accompanied at the surface by more frequent gas emissions, water jetting and a stabilization of the lake level (GeoNet, 2019b), along with elevated $\mathrm{SO}_{2}$ flux detected from satellite observations (Burton et al., 2021). Short, day-long cyclic oscillations are evident in both MF and HF bands (Figure 4c). Since the MF signal is stronger, the oscillations are associated with short-term rises in the unsmoothed DSAR (Figure S7). Each cycle ends with a linear decline of inverse RSAM (Figure 4a), which suggests that cascading material failure is occurring (Voight, 1988).

Taken together, these observations imply that the Nov 23 to Dec 02 period was dominated by pulsatory gas fluxing. Each cycle begins with building MF and DSAR that likely represents pressurization below a blocked conduit or weak seal. The cycle ends with cascading seal failure that renews gas flow paths, and generates surface jetting, accompanied by decrease in MF and DSAR. Sealing in the breccia-filled crater and conduit could be due to deformable clays, pore blockage by elemental sulphur, or rapid sulphate mineral precipitation along thin cracks. Seal failure and crack formation at Whakaari is likely transient (Kennedy et al., 2020). On Dec 02 there was an especially large gas pulse as seen in $\mathrm{SO}_{2}$ flux (Burton et 
al., 2021), which coincides with a strong signal in the smoothed $n D S A R$ rate variance (Figure 4a). This marked the end of the pulsatory regime.

After Dec 03, both the $n M F$ and $n H F$ medians (2-day normalized smoothed MF and HF tremor) decline for a few days, before a reversal and steady rise of the MF signal (regime 3, Figure 4b). Decoupling of MF and HF signals during this period is reflected in a concurrent increase of the $n D S A R$ median (Figure 4a). There was no $\mathrm{SO}_{2}$ flux (Burton et al., 2021) or elevated surface activity reported during this period and we hypothesize that it represents a more efficient seal consolidation and pressurization stage. This is consistent with prior association between short-term MF increase and pressurization in the pulsatory regime, but now with a larger disparity between MF and HF. A sub-surface seal will suppress fluid release, and in-turn dampen surface process (decreases HF signal). Ongoing fluid entry and pressurization below the seal causes stronger MF return, because HF is attenuated as signal transits from the subsurface. The mechanism of seal consolidation is uncertain but could be, e.g., determined by analysis of ballistics (cf., Kilgour et al., 2019).

The forth regime is characterized by a reversal of the $n D S A R$ median, which declines steadily in the days before eruption (regime 4, Figure 4a). The decline mainly reflects a proportionally larger drop in MF (Figure 4b). This 'MF-quieting' likely shows that the reservoir/aquifer below the seal has reached an equilibrium pressure with the current state of deep fluid recharge.

On Dec $08, \sim 16$ hours before the eruption, a burst of activity occurred across all tremor bands (Figure 4c, waveforms in Figure S8), along with a pronounced increase in the 75-minute nHF harmonic (Figure 4a). At the same time, inverse RSAM began a characteristic linear decrease (Figure 4a). This latter pattern was used for prospective (De la Cruz-Reyna et al., 2001) and retrospective (Chardot et al., 2015) forecasting of eruptions using the failure forecast method (FFM; Voight et al.1988; Whitehead et al., 2021). As with the pulsatory regime, this decline is interpreted as cascading material failure, including crack formation within the seal; this eventually allows explosive escape of the pressurized fluids. Notable is a strong $\mathrm{SO}_{2}$ signal up to 40 minutes before the eruption (Burton et al., 2021), likely reflecting the final stages of seal breakdown. The seismic activity burst 16 hours before eruption was recognized by Dempsey et al. (2020) as a precursor and hypothesized to represent a sudden gas/fluid influx. We show here, however, that pressurization and pre-conditioning of the system to eruption can be recognized much earlier.

\section{Conclusions}

Shallow-seated sudden explosive eruptions are notoriously difficult to forecast, especially in wet and noisy volcanoes. We performed a correlation analysis across time-series features derived from tremor data in the weeks preceding 18 sudden explosive eruptions across six volcanoes. We showed that there are common feature patterns, two of which can be precursors - because they are distinct from noneruptive repose. Monitoring for these observables could help to improve real-time eruption forecasting, and provide new tools and warning products, ultimately saving lives, especially at regularly visited touristic volcanoes. 
Two precursors, nDSAR median and nDSAR rate variance, are especially similar across five Whakaari eruptions, and also recognised prior to Ruapehu, Tongariro, and Veniaminof eruptions. We used the Whakaari 2019 eruption to relate these precursors with hydrothermal reservoir sealing and pressurization that primes the system for a phreatic eruption. Five distinct regimes track the onset to such shallow gas and steam-driven eruptions: (1) deep source fluid input into a geothermal reservoir; (2) pulsatory gas fluxing with weak temporary sealing over one or more weeks; (3) strong seal formation over the hydrothermal system several days before the event (4) leading to a critically pressured shallow aquifer (in near-equilibrium with deep gas pressures); before (5) external perturbation, and/or cascading material failure and crack formation over 10-20 hours, leading to final seal breach and explosive decompression.

\section{Methods}

\section{Tremor data processing}

Continuous seismic waveform data were downloaded using ObsPy (Beyreuther et al., 2010) for six broadband stations close to the craters or vents of subject volcanoes (Figure 1; See Table S1). In total, 50 years of data were processed, ensuring that each eruption had at least one month of data prior (Table S2).

The instrument response was removed from the daily waveform data and this was processed to obtain four time-series (data streams): RSAM (real-time seismic amplitude measure), a 10-minute average of the absolute vertical station velocity bandpass filtered between 2 and $5 \mathrm{~Hz} ; \mathrm{MF}$ (medium frequency) and $\mathrm{HF}$ (high-frequency), computed the same as RSAM but using the 4.5 to 8 , and 8 to $16 \mathrm{~Hz}$ frequency bands; and DSAR (displacement seismic amplitude ratio), the ratio between MF and HF bands recalculated for absolute vertical displacement (Caudron et al., 2019; Dempsey et al., 2020).

To isolate continuous signals, outlier detection is used to remove regional and volcano-tectonic (VT) earthquakes before the data streams are calculated. Events with especially long wave-trains, such as large magnitude subduction earthquakes, are removed by computing a two-window (20 minute) movingminimum of the data stream. For comparison between volcanoes, values in each data stream are transformed so they sit on a unit log-normal distribution (or a unit normal in $\log _{10}$-space). This is called zscore normalization and it has been shown to improve classification modeling (Singh and Singh, 2010). Thus, a normalized value of 1 indicates a datapoint at the mean, and a value of 100 indicates the signal is two standard deviations above the mean. Alternative normalization techniques based on station distance are detailed by Aki and Koyanagi (1981) and Thomson and West (2010).

\section{Feature extraction}

Each of the four data streams was subdivided into overlapping 48-hour windows, with each window advancing one data point ( 10 minutes) beyond the previous one. For each window, 524 timeseries features are extracted using the Python package tsfresh (Christ et al., 2018). Features included measures of distribution (parametric: mean, standard deviation; and non-parametric: quantiles, number of 
peaks), autocorrelation, frequency content, linearity and information content (entropy, energy, nonlinearity scores). Feature extraction yields 524 new time-series for each data stream. The effect of window length was explored by Dempsey et al. (2020) and shown not to affect resolution of short-term eruption precursors at Whakaari.

The feature referred to as $n D S A R$ rate variance is labelled in the tsfresh python library to 'change_quantiles_f_agg_"var"_isabs_False_qh_0.6_ql_0.4'. It is calculated as the variance of paired differences (the "rate") for $n D S A R$ values falling in the interquartile range 0.4-0.6. The feature referred to as 75-minute nHF harmonic has the corresponding tsfresh label 'fft_coefficient_coeff_38_attr_"real'" and is the real component of Fourier coefficient 38 , which approximately corresponds to a frequency with period of 75 minutes.

\section{Cross correlation analysis}

For each feature time-series, e.g., nDSAR median, we analyzed four-week subsections prior to each of the 18 eruptions (See Table S2). We calculated standard correlation coefficients (Pearson method) between feature subsections from each eruption pair (see Figure 2a as reference). Once all the feature correlations are calculated $(>40,000)$, we explored the matrices for high values between eruption pairs of eruptions and also clusters of eruptions that present strong correlations (see Figure 2a-b as reference).

\section{Statistical significance tests}

We conduct statistical significance analysis to test whether a pre-eruptive feature with high correlations is differentiable from non-eruptive repose periods. This verifies whether a result from data generated by testing or experimentation is not likely to occur randomly, but is instead attributable to a specific cause.

To test statistical significance analysis, we first select a possible 'signature', which is a four-week preeruptive feature time-series for one eruption. For example, one signature studied here is the $n D S A R$ median prior to the 2019 Whakaari eruption (Figure 2b). The signature is then correlated with equivalent length records from each volcano (e.g., 10 years for Whakaari), shifting forward one day at a time to calculate new correlations. This calculation is performed most efficiently as a convolution. Finally, we collect all correlation coefficients (e.g., 2600 for the Whakaari record) and generate a histogram of their distribution and explore where the pre-eruption values fall (see Figure 2c-d; $\mathrm{p}$-values are shown in Table S3).

To quantify significance, we calculate p-values using a Kolmogorov-Smirnov test (KS test) (see Table S2), which tests whether the pre-eruption correlation coefficients belong to the same distribution as the repose values. For example, a p-value for the archetype nDSAR median Whakaari-2019 (Figures 3a) correlated with the other four Whakaari eruptions generates high correlation coefficients that are very unlikely ( $p$-value of 0.000148 ) to belong to the background distribution. We have tested a combination of archetype patterns and eruptions groups for different volcanoes (Table S3). 
The statistical significance tests were performed over Whakaari, Ruapehu, Tongariro and Veniaminof record given. Records at Pavlof and Bezymiany are too short to perform conclusive statistical analysis (see Table S1).

\section{DATA AVILABILITY}

Raw waveform data for Ruapehu, Tongariro and Whakaari volcanoes can be download from GEONET (https://service-nrt.geonet.org.nz); and for Veniaminof, Pavlof and Bezymiany volcanoes from IRIS (http://service.iris.edu). Both are operable as clients though the FDSN webservice (https://www.fdsn.org/networks/). Rainfall data are available in New Zealand's National Climate Database (https://cliflo.niwa.co.nz/).

\section{CODE AVILABILITY}

The codes required to replicate the results of this study are available at https://github.com/aardid/volc_forecast_tl/tree/transfer-learning, released under the MIT license.

\section{References}

1. Yamaoka, K., Geshi, N., Hashimoto, T., Ingebritsen, S. E. \& Oikawa, T. Special issue "The phreatic eruption of Mt. Ontake volcano in 2014". Earth, Planets Space 68, 1-8 (2016).

2. Dempsey, D.E., Cronin, S.J., Mei, S., \& Kempa-Liehr, A.W. Automatic precursor recognition and realtime forecasting of sudden explosive volcanic eruptions at Whakaari, New Zealand. Nature Communications 11, 3562 https://doi.org/10.1038/s41467-020-17375-2 (2020).

3. Houghton, B.F., Nairn, I.A. The 1976-1982 Strombolian and phreatomagmatic eruptions of White Island,New Zealand: Eruptive and depositional mechanisms at a 'wet' volcano. Bulletin of Volcanology, 54, 25-49 (1991).

4. Kilgour, G., Kennedy, B., Scott, B., Christenson, B., Jolly, A., et al., Whakaari/White Island: a review of New Zealand's most active volcano. New Zealand Journal of Geology and Geophysics, 1-23 (2021).

5. Montanaro, C., Scheu, B., Cronin, S. J., Breard, E. C. P., Lube, G., \& Dingwell, D. B. Experimental estimates of the energy budget of hydrothermal eruptions; application to 2012 Upper Te Maari eruption, New Zealand. Earth Planet. Sci. Lett., 452, 281-294 (2016).

6. Christenson, B. et al. Cyclic processes and factors leading to phreatic eruption events: Insights from the 25 September 2007 eruption through Ruapehu Crater Lake, New Zealand. Journal of Volcanology and Geothermal Research. Res. 191, 15-32 (2010).

7. Heap, M.J., et al. A multidisciplinary approach to quantify the permeability of the Whakaari/White Island volcanic hydrothermal system (Taupo Volcanic Zone, New Zealand). Journal of Volcanology and Geothermal Research, vol. 332, p. 88-108, (2017).

8. Christenson, B.W., \& Wood, C.P. Evolution of a vent-hosted hydrothermal system beneath Ruapehu Crater Lake, New Zealand. Bulletin of Volcanology 55, 547-565, (1993). 
9. Kilgour, G., Manville, V., Della Pasqua, F., Graettinger, A., Hodgson, K. A., \& Jolly, G. E. The 25 September 2007 eruption of Mount Ruapehu, New Zealand: directed ballistics, surtseyan jets, and ice-slurry lahars. Journal of Volcanology and Geothermal Research, 191(1-2), 1-14 (2010).

10. Scolamacchia, T., \& Cronin, S. J. Idiosyncrasies of volcanic sulfur viscosity and the triggering of unheralded volcanic eruptions. Frontiers in Earth Science, 4, 24. (2016).

11. Kanakiya, S., Adam, L., Rowe, M. C., Lindsay, J. M., \& Esteban, L. The role of tuffs in sealing volcanic conduits. Geophysical Research Letters, e2021GL095175, (2021).

12. Chouet, B.A., Long-period volcano seismicity: Its source and use in eruption forecasting: Nature, v. 380, p., (1996).

13. Konstantinou, K.I., and Schlindwein, V., Nature, wavefield properties and source mechanism of volcanic tremor: A review. Journal of Volcanology and Geothermal Research, v. 119, p. 161-187, https:// doi.org /10 .1016 /S0377 -<background-color:\#D279AA;>0273</backgroundcolor:\#D279AA;> (02)00311 <-background-color:\#D279AA;>6</background-color:\#D279AA;>, (2003).

14. Jellinek, A.M., and Bercovici, D., Seismic tremors and magma wagging during explosive volcanism: Nature, v. 470, p. 522-525, https://doi.org /10 .1038 /nature09828, (2011).

15. Fee, D., Haney, M.M., Matoza, R.S., Eaton, A.R., Cervelli, P., Schneider, D.J., and Lezzi, A.M., Volcanic tremor and plume height hysteresis from Pavlof volcano, Alaska: Science, v. 355, p. 45-48, https://doi.org/10.1126/science.aah6108 (2017).

16. Caudron, C., Girona, T., Jolly, A., Christenson, B.W., et. al., A quest for unrest in multiparameter observations at Whakaari/White Island volcano, New Zealand 2007-2018. Earth, Planets and Space, 73(1), 1-21 (2021).

17. Gottsmann, J. et al. Oscillations in hydrothermal systems as a source of periodic unrest at caldera volcanoes: Multiparameter insights from Nisyros, Greece. Geophysical Research Letters 34, 5 (2007).

18. Ohminato, T. Characteristics and source modeling of broadband seismic signals associated with the hydrothermal system at Satsuma Iwojima volcano, Japan. Journal of Volcanology and Geothermal Research. 158, 467-490 (2006).

19. Caudron, C., Girona, T., Taisne, B. \& Gunawan, H. Change in seismic attenuation as a long-term precursor of gas-driven eruptions. Geology 47, 632-636 (2019).

20. Gunawan, H., Caudron, C., Pallister, J., Primulyana, S., Christenson, B., Mccausland, W., ... Hendrasto, $M$. New insights into Kawah ljen's volcanic system from the wet volcano workshop experiment. Geological Society, London, Special Publications, 437(1), 35-56, (2017).

21. Pardo, Natalia, et al. Perils in distinguishing phreatic from phreatomagmatic ash; insights into the eruption mechanisms of the 6 August 2012 Mt. Tongariro eruption, New Zealand. Journal of Volcanology and Geothermal Research 286: 397-414, (2014).

22. Yamada, T., Kurokawa, A.K., Terada, A., Kanda, W., Ueda, H., Aoyama, H., Ohkura, T., Ogawa, Y., Tanada, T. Locating hydrothermal fluid injection of the 2018 phreatic eruption at Kusatsu Shirane volcano with volcanic tremor amplitude. Earth Planet Space 73:14. https://doi.org/10.1186/s40623020-01349-1, (2021). 
23. Jolly, A., Caudron, C., Girona, T., Christenson, B., \& Carniel, R. 'Silent' Dome Emplacement into a Wet Volcano: Observations from an Effusive Eruption at White Island (Whakaari), New Zealand in Late 2012. Geosciences. 10(4):142. https://doi.org/10.3390/geosciences10040142, (2020).

24. De Moor, J. M., et al. Insights on hydrothermal-magmatic interactions and eruptive processes at Poás Volcano (Costa Rica) from high-frequency gas monitoring and drone measurements. Geophysical Research Letters, 46(3), 1293-1302, (2019).

25. Endo, E. T., \& Murray, T., Real-time seismic amplitude measurement (RSAM): a volcano monitoring and prediction tool. Bulletin of Volcanology, 53(7), 533-545, (1991).

26. Aki, K., \& Koyanagi, R., Deep volcanic tremor and magma ascent mechanism under Kilauea, Hawaii. Journal of Geophysical Research: Solid Earth, 86(B8), 7095-7109, (1981).

27. McNutt, S. R., Volcanic tremor from around the world: 1992 update. Acta Vulc., 5, 197-200, (1994).

28. Chardot, L., Jolly, A. D., Kennedy, B. M., Fournier, N., \& Sherburn, S. Using volcanic tremor for eruption forecasting at White Island volcano (Whakaari), New Zealand. Journal of Volcanology and Geothermal Research, 302, 11-23, (2015).

29. Reichstein, M. et al. Deep learning and process understanding for data-driven Earth system science. Nature 566, 195-204 (2019).

30. Hajian, A., Cannavò, F., Greco, F. \& Nunnari, G. Classification of Mt Etna (Italy) volcanic activity by machine learning approaches. Annals of Geophysics 62, 231 (2019).

31. Langer, H., Falsaperla, S., Messina, A., Spampinato, S. \& Behncke, B. Detecting imminent eruptive activity at Mt Etna, Italy, in 2007-2008 through pattern classification of volcanic tremor data. Journal of Volcanology and Geothermal Research 200, 1-17 (2011).

32. Brancato, A. et al. K-CM application for supervised pattern recognition at Mt. Etna: an innovative tool to forecast flank eruptive activity. Bulletin of Volcanology 81, 40 (2019).

33. Voight, B., 1988. A method for prediction of volcanic eruptions. Nature 332 (6160), 125-130.

34. GeoNet, Volcanic Alert Bulletin WI-2019/09. https://www.geonet.org.nz/vabs/1prVlz8jGXwWayA8D6Uu5y, (2019a).

35. Potter, S. H., Jolly, G. E., Neall, V. E., Johnston, D. M., \& Scott, B. J. Communicating the status of volcanic activity: revising New Zealand's volcanic alert level system. Journal of Applied Volcanology, 3(1), 1-16. (2014).

36. GeoNet, Volcanic Alert Bulletin WI-2019/10. https://www.geonet.org.nz/vabs/7sXDNIKK9uRvcNKtH9UFbB, (2019b).

37. Kennedy, B. M., et al. Pressure controlled permeability in a conduit filled with fractured hydrothermal breccia reconstructed from ballistics from Whakaari (White Island), New Zealand. Geosciences, 10(4), 138. (2020).

38. Kilgour, G.N., Gates, S., Kennedy, B., Farquhar, A., McSporran, A., Asher, C. Phreatic eruption dynamics derived from deposit analysis: A case study from a small, phreatic eruption from Whakaari/White Island, New Zealand. Earth Planets Space, 71, 36, (2019). 
39. De la Cruz-Reyna, S. \& Reyes-Dávila, G. A. A model to describe precursory material-failure phenomena: applications to short-term forecasting at Colima volcano, Mexico. Bulletin of Volcanology 63, 297-308, (2001).

40. Whitehead, M. G., \& Bebbington, M. S. Method selection in short-term eruption forecasting. Journal of Volcanology and Geothermal Research, 107386. (2021).

\section{Declarations}

\section{Acknowledgements}

Tremor data were supplied by the GEONET (New Zealand) and AVO (Alaskan Volcano Observatory, USA) seismic monitoring system. Maps shown in Figure are modified from Google Earth.

Photos from Figure 1 correspond to (from top to bottom): Whakaari (De James Shook, CC BY 2.5, https://commons. wikimedia.org/w/index.php?curid=8645905), Ruapehu (De Michal Klajban Trabajo propio, CC BY-SA 4.0, https://commons. wikimedia.org/w/index.php?curid=39988630), Pavlof (By U.S. Fish and Wildlife Service - images.fws.gov, Public Domain, https://commons.wikimedia.org/w/index.php?curid=3534132), Bezymiany (De Dan Miller, U.S. Geological Survey - http://www.volcano.si.edu/world/volcano.cfm?vnum=100025=\&amp;volpage=photos\&amp;photo=024049, Public Domain, https://commons.wikimedia.org/w/index.php?curid=3917792), Veniaminof (De Hood R E, U.S. Fish and Wildlife Service - http://www.public-domain-image.com/public-domain-images-pictures-freestock-photos/nature-landscapes-public-domain-images-pictures/mountain-public-domain-imagespictures/mountain-veniaminof-black-lake-landscape.jpg, Public Domain, https://commons.wikimedia.org/w/index.php?curid=24911753), Tongariro (De The original uploader was Grutness de Wikipedia en inglés. - Transferido desde en.wikipedia a Commons., CC BY-SA 3.0, https://commons. wikimedia.org/w/index.php?curid=3209038).

\section{Figures}

\section{Figure 1}

Locations of the six volcanoes in this study: Whakaari, Tongariro, and Ruapehu in New Zealand (left panel; TVZ: Taupo Volcanic Zone), Veniaminof and Pavlof in Alaska, USA, and Bezymiany in the Kamchatka Peninsula, Russia (top panel). The central panel shows time-series for the feature nDSAR rate variance (red) prior to six major eruptions (black dashed line) at each volcano. The raw DSAR data time series is shown in the background (light blue). VEI=Volcano Explosivity Index. 


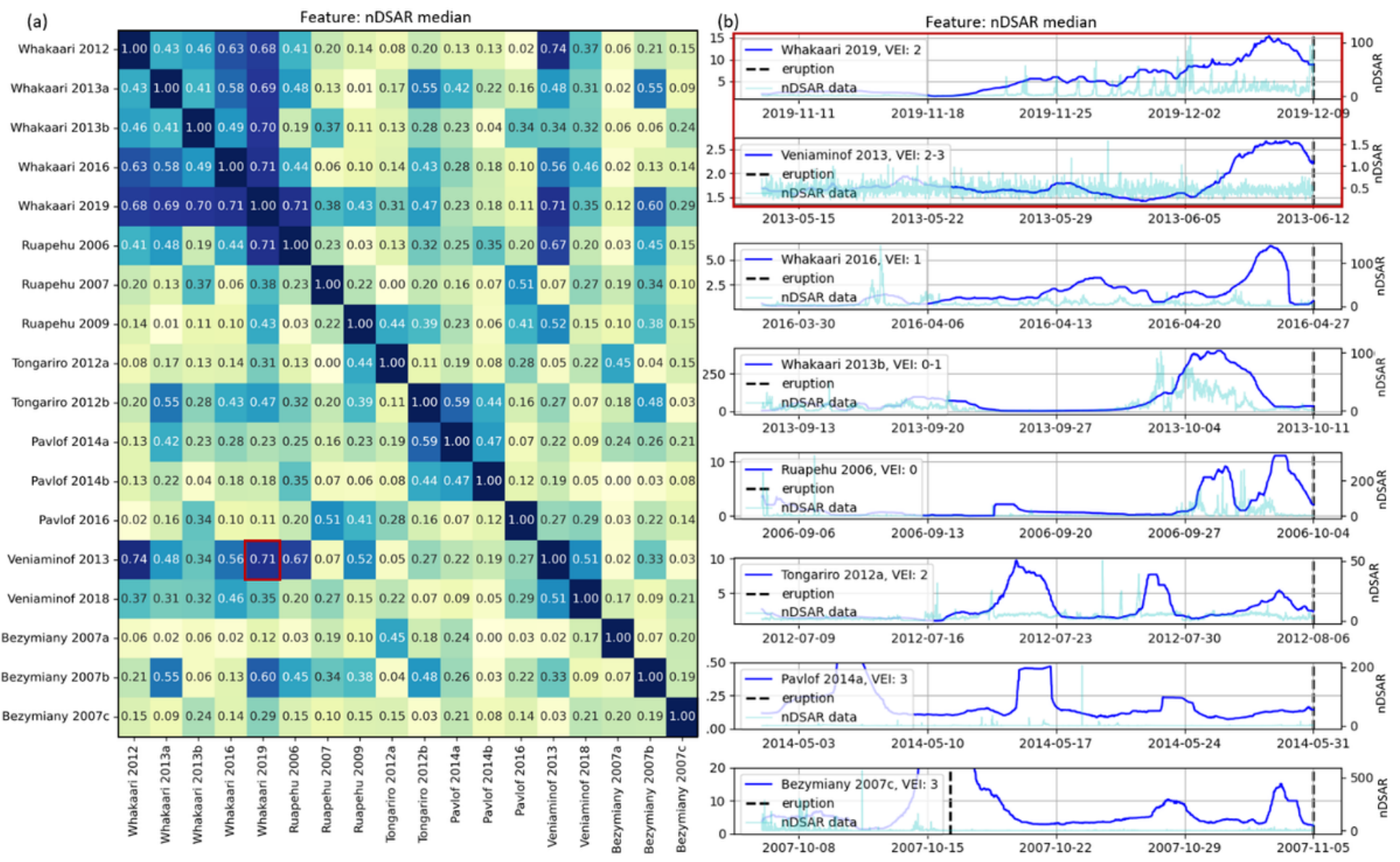

Figure 2

(a) Matrix of correlation coefficients between eruption pairs for the four-week DSAR median. The red outlined square corresponds to correlation between the pair of eruptions, Whakaari 2019 and Veniaminof 2013, shown in detail red outlined top panels on the righthand side. (b) One-month pre-eruptive time series of smoothed DSAR (blue) prior to eight eruptions (black dashed line; for all eruptions see Fig. SX?). Raw DSAR data are shown in light blue. 
Feature nDSAR median in Whakaari 2019 eruption over Veniaminof, Tongariro, Whakaari and Ruapehu records

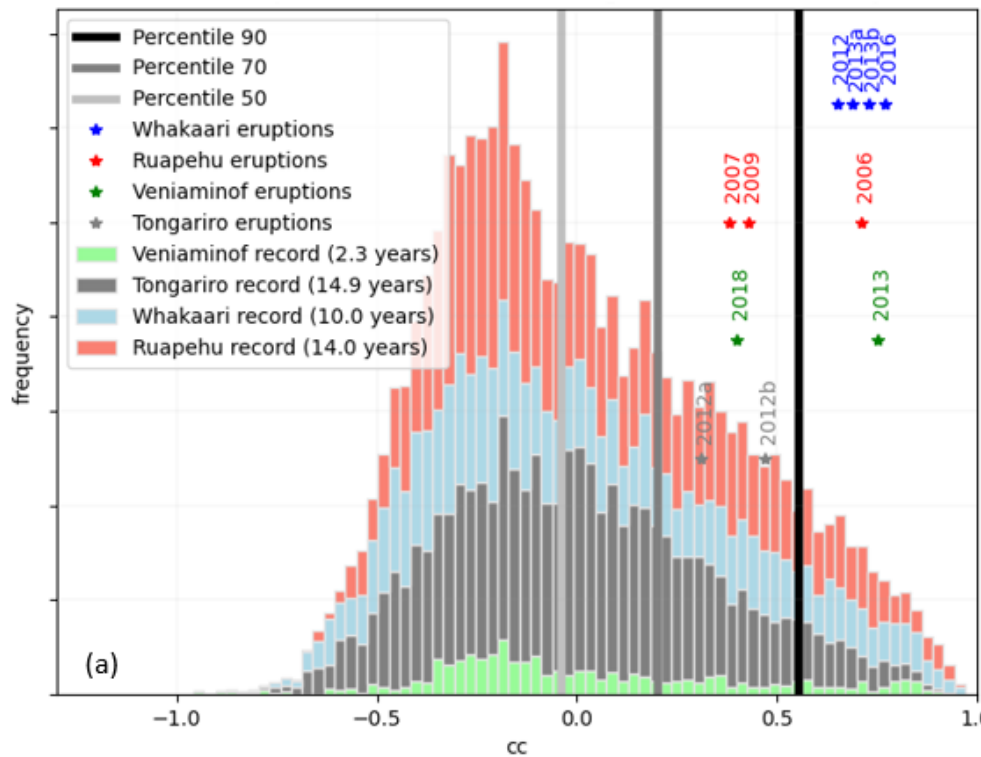

cc
Feature nDSAR rate variance in Whakaari 2019 eruption over Veniaminof, Tongariro, Whakaari and Ruapehu records

Feature 75-minute nHF harmonic in Whakaari 2019 eruption over

Veniaminof, Whakaari and Ruapehu records

(b)

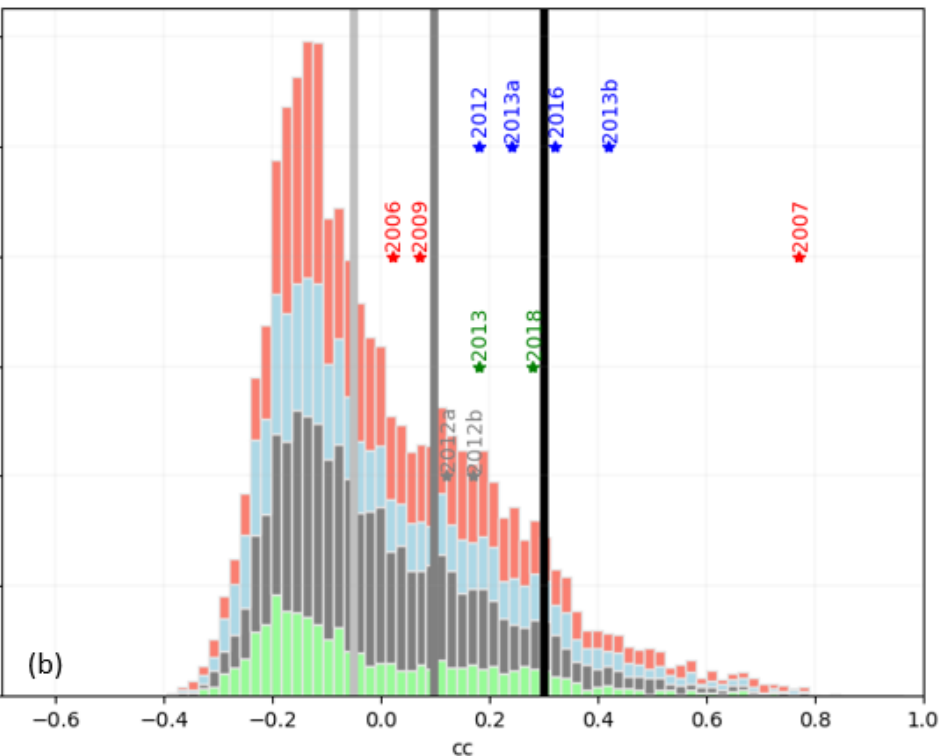

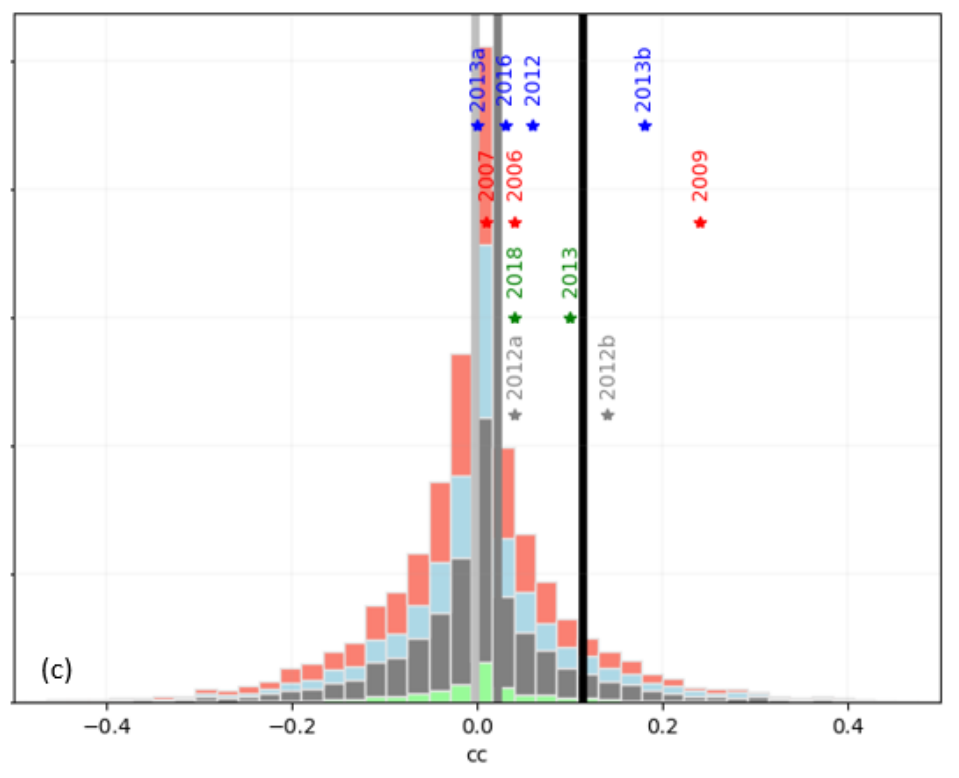

Figure 3

Statistical significance analysis for potential precursors (a) DSAR median, (b) DSAR rate variance and (c) 75-minute HF harmonic, using corresponding feature time series four-weeks prior to the 2019 Whakaari eruption as archtypes. Distribution of daily correlation coefficients for these archetypes are shown over the available Whakaari (blue), Ruapehu (red), Tongariro (grey) and Veniaminof records (green). Preeruption correlations are labelled by year of eruption and using the corresponding volcano color. Vertical offset is for ease of distinction only. Median, 70th and 90th percentiles are shown as increasingly darker grey vertical bars. 

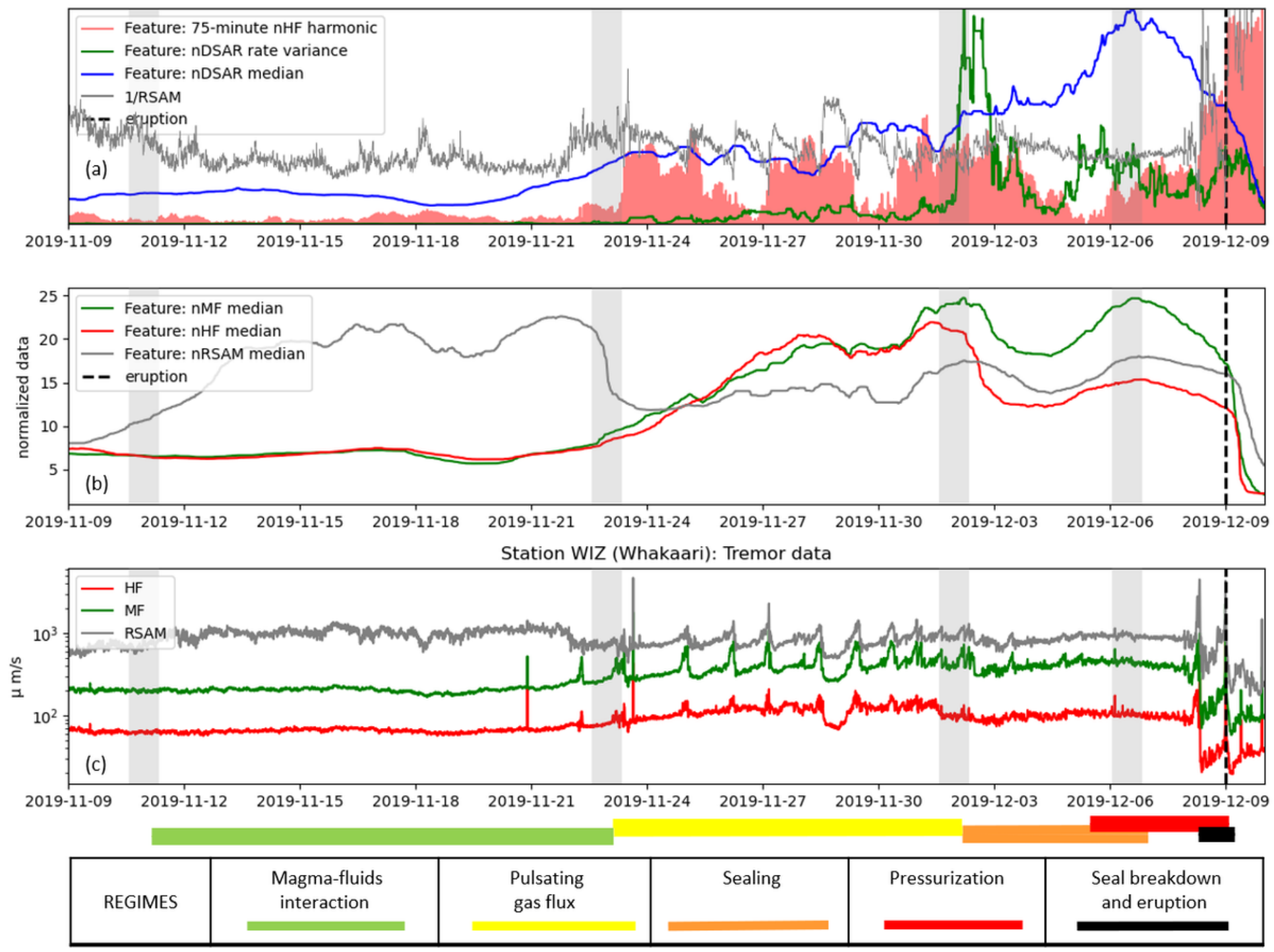

Figure 4

Four-week pre-eruptive time series for the Whakaari 2019 eruption: (a) DSAR median archetype (blue), DSAR rate variance (green), 75-minute HF harmonic (red), and inverse RSAM (grey); (b) 2-day moving medians for normalized MF (green), HF (red), and RSAM (grey); (c) raw, unsmoothed MF, HF and RSAM. Vertical grey bands mark approximate divisions of the four regimes labelled at based of the figure.

\section{Supplementary Files}

This is a list of supplementary files associated with this preprint. Click to download.

- SIrev20211116.docx 